\title{
Phase V Trial
}

National Cancer Institute

\section{Source}

National Cancer Institute. Phase V Trial. NCI Thesaurus. Code C47865.

Postmarketing surveillance is sometimes referred to as Phase V. See outcomes research. 